\title{
Versorgung von Freienden mit Monoreduktor
}

In Zeiten des Implantats sind herausnehmbare Lösungen für Freienden häufig nicht mehr 1. Wahl. Aber bei Kontraindikation für Implantate oder wirtschaftlichen Zwängen kann die Riegelprothese durchaus eine funktionelle und ästhetische Al-

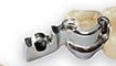

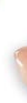
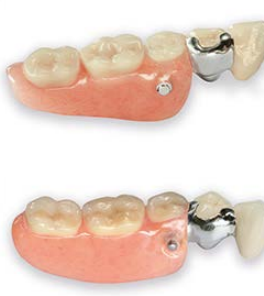

ternati-

ve sein.

Nicht je-

des uni-

laterale

Freiende

führt so

automa-

tisch zu

einem mitunter unangenehmen Sublingualbügel oder großen Verbinder. Auch auf störende Klammern kann ganz verzichtet werden.

Riegelversorgungen müssen nur zum Reinigen entnommen werden und bilden ansonsten eine starre Verbindung mit den mindestens 2 überkronten Zähnen. Auch ein Schubverteilungsarm sollte geplant werden. Kommen Implantate also nicht in Frage, kann ein Monoreduktor manchmal sogar 1. Wahl für die komfortable Versorgung einer solchen Mundsituation sein.

Nach einer Pressemitteilung der

Permadental GmbH, Emmerich www.permadental.de 